Article

\title{
Association of Graphene Silver Polymethyl Methacrylate (PMMA) with Photodynamic Therapy for Inactivation of Halitosis Responsible Bacteria in Denture Wearers
}

\author{
Cecilia Bacali ${ }^{1,+}$ Rahela Carpa $^{2, *} \mathbb{0}$, Smaranda Buduru ${ }^{1,+}$, Mirela L. Moldovan ${ }^{3} \mathbb{D}$, Ioana Baldea ${ }^{4}$, \\ Annemarie Constantin ${ }^{5}$, Marioara Moldovan ${ }^{6}\left(\mathbb{D}\right.$, Doina Prodan ${ }^{6}$, Laura Monica Dascalu (Rusu) ${ }^{1}$, \\ Ondine Lucaciu ${ }^{7}$ (D) Florinela Catoi ${ }^{8}$, Mariana Constantiniuc ${ }^{1}$ and Mandra Badea ${ }^{9}$
}

check for updates

Citation: Bacali, C.; Carpa, R.; Buduru, S.; Moldovan, M.L.; Baldea, I.; Constantin, A.; Moldovan, M.; Prodan, D.; Dascalu, L.M.; Lucaciu, O.; et al. Association of Graphene Silver Polymethyl Methacrylate (PMMA) with Photodynamic

Therapy for Inactivation of Halitosis Responsible Bacteria in Denture Wearers. Nanomaterials 2021, 11, 1643. https://doi.org/10.3390/ nano11071643

Academic Editor: Cristina Martín

Received: 7 May 2021

Accepted: 21 June 2021

Published: 23 June 2021

Publisher's Note: MDPI stays neutral with regard to jurisdictional claims in published maps and institutional affiliations.

Copyright: (c) 2021 by the authors. Licensee MDPI, Basel, Switzerland. This article is an open access article distributed under the terms and conditions of the Creative Commons Attribution (CC BY) license (https:/ / creativecommons.org/licenses/by/ $4.0 /)$.
1 Department of Prosthodontics and Dental Materials, Iuliu Hatieganu University of Medicine and Pharmacy, Clinicilor 32, 400006 Cluj-Napoca, Romania; cecilia.bacali@yahoo.com (C.B.); smarandabuduru@yahoo.com (S.B.); rusu.monica.laura@gmail.com (L.M.D.); mconstantiniuc@umfcluj.ro (M.C.)

2 Department of Molecular Biology and Biotechnology, Faculty of Biology and Geology, Babeș Bolyai University, 1 M. Kogălniceanu Street, 400084 Cluj-Napoca, Romania

3 Department of Dermopharmacy and Cosmetics, Faculty of Pharmacy, Iuliu Hatieganu University of Medicine and Pharmacy, 12 I. Creanga Street, 400010 Cluj-Napoca, Romania; mmoldovan@umfcluj.ro

4 Department of Physiology, Iuliu Hatieganu University of Medicine and Pharmacy, Clinicilor, 400006 Cluj-Napoca, Romania; baldeaioana@gmail.com

5 Department of Morphological Sciences, Iuliu Hatieganu University of Medicine and Pharmacy, 6 L. Pasteur, 400335 Cluj-Napoca, Romania; annemarie_chindris@yahoo.com

6 Raluca Ripan Institute for Research in Chemistry, Fantanele 30, Babeș Bolyai University, 400294 Cluj-Napoca, Romania; mmarioara2004@yahoo.com (M.M.); doina_prodan@yahoo.com (D.P.)

7 Department of Oral Health, Iuliu Hatieganu University of Medicine and Pharmacy, Avram Iancu 31, 400083 Cluj-Napoca, Romania; ondineluc@yahoo.com

8 Department of Functional Biosciences, Iuliu Hatieganu University of Medicine and Pharmacy, Avram Iancu 31, 400083 Cluj-Napoca, Romania; adriana.catoi@umfcluj.ro

9 Department of Preventive Dental Medicine, Iuliu Hatieganu University of Medicine and Pharmacy, Avram Iancu 31, 400083 Cluj-Napoca, Romania; mebadea@umfcluj.ro

* Correspondence: rahela.carpa@ubbcluj.ro; Tel.: +40-721893575

+ These authors contributed equally to this work.

Abstract: (1) Background: Poor hygiene and denture presence in the oral cavity are factors that favor bacterial accumulation, the cause of halitosis and of various oral and general diseases. Aim: This study aimed to evaluate the possibility of inactivating bacteria associated with halitosis in acrylic denture wearers using polymethyl methacrylate resin enhanced with graphene silver nanoparticles and the effect of the resin association with extra oral photodynamic therapy. (2) Methods: Graphene silver nanoparticles in 1 and $2 \mathrm{wt} \%$ were added to a commercial acrylic resin powder. Three study groups containing samples from the three different materials were established. The first group was not exposed to the light treatment, and the other two were exposed to red light (laser and light emitting diode) after photosensitizer placement on the disk's surface. Samples were incubated with Porphyromonas gingivalis and Enterococcus faecalis. (3) Results: For both bacterial strains, inhibition zones were obtained, showing significant differences for the light-treated samples. (4) Conclusions: Denture resins with antibacterial properties associated with extra oral photodynamic therapy exhibited enhanced antibacterial effects. The procedure could be used as a safer and more efficient alternative technique against halitosis and oral infections in denture wearers.

Keywords: halitosis; graphene; photodynamic therapy; Enterococcus faecalis; Porphyromonas gingivalis

\section{Introduction}

Inadequate oral hygiene, characterized by accumulation of food debris, increased denture plaque, and tongue deposits in denture wearers is the major cause for oral malodor 
by promoting bacterial accumulation in the oral cavity. Denture plaque is a reservoir of pathogenic bacteria that can be associated with different oral conditions and with major geriatric health problems [1,2]. Microbial intensive growth is favored by the tongue and saliva-reduced cleaning actions and by the anaerobic habitat found under the denture base.

Significant associations between bad breath and tongue deposits, denture quality, overnight denture wearing, systemic diseases, and medicine intake were found [3]. The prevalence of volatile sulphur compounds like hydrogen sulphide $\left(\mathrm{H}_{2} \mathrm{~S}\right)$ was found to be significantly higher among denture wearers compared with subjects without dentures, with $\mathrm{H}_{2} \mathrm{~S}$ being associated with tongue deposits and overnight denture wearing, while dimethyl sulphide $\left(\mathrm{CH}_{3}\right)_{2} \mathrm{~S}$ was associated with systemic diseases and the intake of medicines [3]. An extreme reduction of resting salivary flow and increased tongue coating were also associated with higher levels of $\mathrm{H}_{2} \mathrm{~S}$ and methyl mercaptan $\left(\mathrm{CH}_{3} \mathrm{SH}\right)$ [4]. Decreased salivary flow in the case of systemic conditions, medication, or during nighttime can increase the intensity of halitosis [5].

Gram-negative oral bacteria are considered the main factor responsible for the production of volatile sulphur compounds associated with oral malodor-methyl mercaptan, hydrogen sulphide, dimethyl sulphide - and other malodorous substances (diamines as putrescine and cadaverine or butyric, valeric, or propionic acids) [6,7]. Enterococcus faecalis proved to be one of the predominant bacteria present in removable-denture wearers and was also associated with halitosis [8]. Higher amounts of Enterobacteriaceae are present in the oral environment of denture wearers $(48 \%)$, compared with the normal population $(16.4 \%)$, and the incubation of this bacterial strain on a sterile denture was shown to produce the characteristic denture odor. Porphyromonas gingivalis is another main bacterium involved in oral malodor [9].

Although an improvement of oral hygiene can be obtained by mechanical methods such as brushing or by chemical methods that use mouthwash solutions or cleansing tablets with antimicrobial effects, they have limited efficiency [10].

Polymethyl methacrylate (PMMA) is the most often-used material in denture fabrication, but it has several shortcomings, among them being the strength [11] and the antibacterial activity. Studies showed that bacterial adhesion to polymethyl methacrylate surfaces seems to be reduced when compared with other acrylic denture base materials, like polyethylene terephthalate (PET), and consequently PMMA would be more recommended for patients with inadequate hygiene and halitosis [12]. However, the presence of the acrylic materials in the oral cavity enables bacterial adhesion and biofilm formation, also favoring inflammation of oral tissues and halitosis [13].

The finishing and polishing procedures can influence the roughness and gloss of resin-based materials and can also have an important role in biofilm formation [14]. Studies showed that material composition and characteristics play a bigger role in bacterial adhesion than the surface roughness [15]. Addition of different nanoparticles can improve the acrylic resins' properties (antibacterial, antifungal, and mechanical properties), as was shown in many studies [16-18].

In the recent years, the effect of nanofiller addition to different materials was evaluated because of an increasing interest towards medical $[19,20]$ and dental materials [21] and antimicrobial and mechanical properties improvement. The addition of silver nanoparticles to acrylic resins has shown an efficient antimicrobial action [22], while the addition of silver nanoparticles and graphene improved both mechanical [18] and antimicrobial properties of a denture resin [23].

Photodynamic therapy (PDT) is a minimally invasive and minimally toxic treatment for destroying bacteria or diseased cells, and is based on a photochemical reaction that uses a light sensitive photosensitizer. The photo-sensitive substance is activated by exposure to a specific light beam before toxic products for the targeted cells are released [24]. The antibacterial effect is possible due to the production of reactive oxygen species, especially singlet oxygen [24]. PDT destroys selective cells in a short time, can be applied to wide surfaces, and can be repeated easily, with portable devices being available [25]. Visible 
light was also shown to have effects on the odoriferous components [26]. In a study which assessed the effect of visible light against Porphyromonas gingivalis, a reduction in the bacterial count was obtained, which suggested the possibility of using PDT as a prophylactic treatment with no side effects [27]. However, photosensitizing effects of PDT on the skin tissues were reported [28]. Other early or late onset side effects, such as pain, burns, erythema, and desquamation can occur following PDT, causing discomfort for the patient [25].

The possibility of inactivating the halitosis-responsible bacteria using improved denture materials and also the new approaches of enhancement of the acrylic resin's antibacterial effect using associations of safe techniques could be highly beneficial for denture or orthodontic device-wearing patients. The aim of this study was to evaluate the possibility of inactivating oral bacteria associated with halitosis in acrylic denture wearers using polymethyl methacrylate (PMMA) resin enhanced with graphene silver nanoparticles with and without the association of extra oral photodynamic therapy (PDT). The null hypothesis was that the enhanced resins have no effect on halitosis-responsible bacteria.

\section{Materials and Methods}

\subsection{Acrylic Samples Preparation}

Graphene silver nanoparticles were synthetized by the radio frequency catalytic chemical vapor deposition (RF-CCVD) method, using silver nanoparticles distributed over magnesium oxide ( $\mathrm{ggx} / \mathrm{MgO}$, where $\mathrm{x}=3 \mathrm{wt} \%)$ as described in a previous study [29]. Then, they were added to a commercial acrylic resin powder, Castavaria (Vertex Dental, Zeist, The Netherlands), in $1 \%$ and $2 \%$ weight percentages, using a lab-vibrating device [23]. After mixing the monomer and the polymer in the recommended ratio $(1 \mathrm{~mL} / 0.95 \mathrm{~g}$ monomer: $1.7 \mathrm{~g}$ polymer), the material was poured in a silicone mold (stick shaped) and cured for $30 \mathrm{~min}$ at $55^{\circ} \mathrm{C}$ and 2.5 Barr in a polymerizing unit, according to the producer's specifications, resulting sticks of $15 \times 5 \mathrm{~mm}$. Disks $5 \mathrm{~mm}$ in diameter and $1 \mathrm{~mm}$ in thickness were obtained by cutting the sticks with a cutting device (Isomet 1000, Precision Saw, Buehler, ITW, IL, USA) and divided into three study groups: C (control—simple resin), $\mathrm{P} 1$ (resin with $1 \mathrm{wt} \%$ graphene silver nanoparticles), and P2 (resin with $2 \mathrm{wt} \%$ graphene silver nanoparticles).

\subsection{Acrylic Samples Investigations}

\subsubsection{Cross Polarized Light Microscopy (CPOM)}

The powders used in the study were characterized by Cross Polarized Light Microscopy (CPOM) to observe in which manner graphene-silver powder coated the polymer spheres. Therefore, the investigation was performed on a Laboval II Mineralogical Microscope (Karl Zeiss Jena, Oberkochen, Germany) equipped with a Samsung digital camera $8 \mathrm{MPx}$, (Samsung, Seoul, Korea).

\subsubsection{FT-IR Spectroscopy}

FT-IR Spectroscopy was used to detect the functional groups, specific for the studied materials. An Able Jasco 610 instrument (ABL\&E-JASCO Group, Wien, Austria) in the range of 4000 to $500 \mathrm{~cm}^{-1}$ was used.

\subsubsection{Scanning Electron Microscopy}

The investigation was performed at 10,000 $\times$ magnitude in a low-vacuum, pressure of $80 \mathrm{~Pa}$, at $15 \mathrm{kV}$ and $11 \mathrm{~mm}$ working distance.

\subsection{In Vitro Testing of the Acrylic Samples' Toxicity}

Cell cultures. The assays were performed on human gingival fibroblasts-HGF (ATCC CRL-2014, HGF-1, LOT: 63449675) purchased from ATCC (Manassas, VA, USA). The cell culture medium was DMEM, supplemented with 10\% FBS (Fetal Bovine Serum), 
antibiotics, and antimycotics. All reagents were purchased from Sigma Aldrich, Co., Heidelberg, Germany.

Extract preparation. The samples from all three studied groups were sterilized by immersion in ethanol $70^{\circ}$ for $30 \mathrm{~s}$ and then washed three times in sterile PBS. The disks were then incubated for $24 \mathrm{~h}$ at $37^{\circ} \mathrm{C}$ with the cell culture medium at a concentration of $3 \mathrm{~cm}^{2} / \mathrm{mL}$, complying with the ISO 10993-12/2012 procedures [30]. The extract was immediately used for the experiments.

Viability assay. Cell survival was assessed using CellTiter $96{ }^{\circledR}$ AQueous Non-Radioactive Cell Proliferation Assay (Promega Corporation, Madison, WI, USA). The cells were cultivated at a density of 104/well in 96-well plates (TPP, Trasadingen, Switzerland) for $24 \mathrm{~h}$, then exposed to extracts of the samples diluted in medium for $24 \mathrm{~h}$ at a dilution range of 0-64×. Viability was measured by colorimetric analysis using an ELISA plate reader (Tecan, Männedorf, Switzerland) at $540 \mathrm{~nm}$. All experiments were done in triplicate. Untreated cell cultures were used as controls. Results are presented as OD540.

Phaloidin staining. Phalloidin-FITC $50 \mu \mathrm{g} / \mathrm{mL}$ (Sigma Chemical Co., St. Louis, MO, USA) a marker for actin myofilaments (green)—was used according to the manufacturer's instructions. HGF cells were seeded in chamber slides at a density of $5 \times 10^{4} /$ chamber, allowed to settle for $24 \mathrm{~h}$, and then exposed to the undiluted extract of each sample. Controls were exposed only to the medium. The treated cells were then stained with phalloidin-FITC. Images of cells were documented using an inverted microscope Olympus BX40 equipped with an Olympus CKX-RFA fluorescent lamp and an E330 camera (Olympus, Hamburg, Germany) at a magnification of $20 \times$.

\subsection{Antibacterial Assays}

The microorganisms tested in this study were Porphyromonas gingivalis ATCC 33277 and Enterococcus faecalis ATCC-29212, from the Microbiology Lab, Faculty of Biology and Geology, UBB, Cluj-Napoca. Diffusometric analysis was used for the evaluation of the antimicrobial activity. Aseptic disks $5 \mathrm{~mm}$ in diameter and $1 \mathrm{~mm}$ in thickness prepared from the three types of materials were used as acrylic resin samples. Bacterial suspensions from the fresh strains were prepared in normal saline solution and adjusted to a $0.5 \mathrm{McFarland}$ turbidity. Mueller-Hinton culture medium (Oxoid, UK) was used to inoculate the bacterial suspensions [31].

After the samples were made, they were divided into three study groups, each of them containing C (simple resin), P1 (resin with 1\% graphene silver nanoparticles), and P2 (resin with $2 \%$ graphene silver nanoparticles). The samples obtained from the resin without the addition of nanoparticles were used as control. The first study group was not exposed to light treatment; the second group was exposed to diode light after FotoSan Agent placement on the disk surface and the third group was exposed to laser light after the placement Helbo Blue Photosensitizer on the sample surface. The disks were exposed to the light for $3 \mathrm{~min}$. A portable light emitting diode FotoSan 630 (CMS Dental, $630 \mathrm{~nm}$ wavelength, 2000-4000 $\mathrm{nw} / \mathrm{cm}^{2}$ ) and a therapeutic red laser, Helbo TheraLite Laser (Bredent Medical $\mathrm{GmbH \& CO}$, Germany, $660 \mathrm{~nm}$ wavelength), were used as light sources.

The disks from each group were then placed on plates seeded separately with the two bacterial strains to assess their antimicrobial activity. After incubation at $37^{\circ} \mathrm{C}$ for $48 \mathrm{~h}$, the inhibition zones were measured using an inhibition-zone-measuring scale. All assays were performed in triplicate, under aseptic conditions.

\subsection{Scanning Electron Microscopy (SEM) Investigations of the Bacterial Cells}

Porphyromonas gingivalis and Enterococcus faecalis incubated for $24 \mathrm{~h}$ at $37{ }^{\circ} \mathrm{C}$ were analyzed using scanning-electron microscopy. After the incubation, preparations were completed and then fixed on the layer of the double-adhesive carbon strip on the mount in the Chemistry Lab of Raluca Ripan Institute for Research in Chemistry. The examination of the surface microstructure was performed using an Inspect S Scanning Electron Microscope 
(FEI Company, Eindhoven, The Netherlands). The determinations were performed in a low vacuum, at a pressure of $80 \mathrm{~Pa}$, at $15 \mathrm{kV}$ and a work distance of $11 \mathrm{~mm}$.

\subsection{Statistical Analysis}

The statistical differences between the experimental groups were evaluated by oneway ANOVA and the paired Student $t$ test, followed by the Bonferroni posttest using GraphPad. Results were considered significant for $p \leq 0.05$. The statistical package used for data analysis was Prism version 4.00 for Windows, GraphPad Software, San Diego, CA, USA.

The statistical difference between the antimicrobial activity of the samples $(n=5)$ were evaluated using one-way ANOVA and the Tukey test for post hoc comparisons between groups. The significance level was set at $p=0.05$. Origin2019b Graphing and Analysis software was used. All the values in text and figures are expressed as mean \pm standard deviation. The results were considered significant for $p \leq 0.05$.

\section{Results}

\subsection{Acrylic Samples Investigations}

\subsubsection{Cross Polarized Light Microscopy}

The biologic effect of the experimental materials was in a close connection with the micro-structural disposal of the graphene-silver powder on the polymer spheres. CPOM images in Figure 1 provide a proper characterization of the coating process.
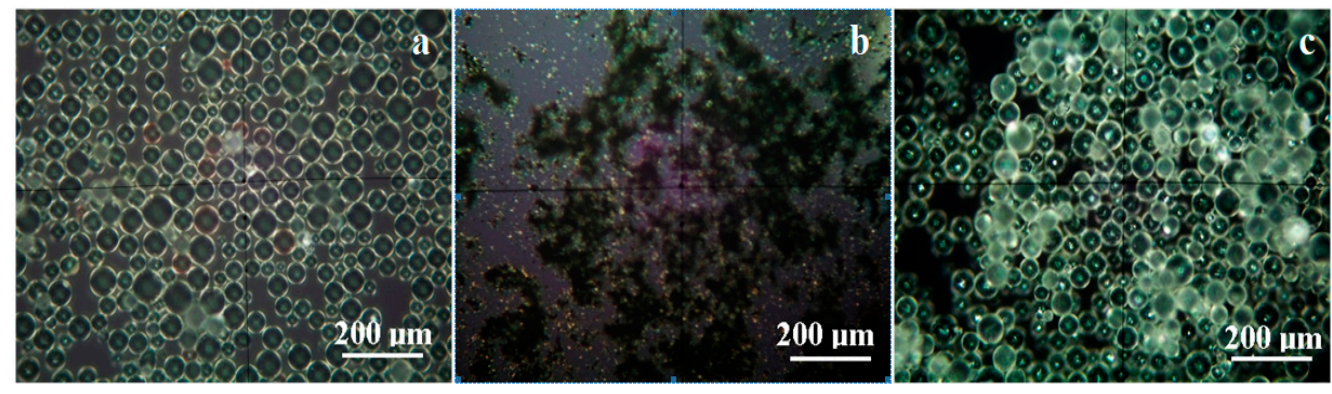

Figure 1. Cross-polarized light microscopy images of the powders: (a) polymer spheres (M), (b) graphene-silver, and (c) polymer spheres coated with graphene-silver (P2).

Polymer powder consists of micro-sized spheres with diameters in a range of about 20 to $50 \mu \mathrm{m}$, Figure 1a. Their aspect features a bright white of the circumference border and a pale-shadow halo inside. The aspect is correlated with the low crystallinity of the polymer.

Graphene-silver powder has a complex mixture of very fine graphene particles organized in micro-sized clusters with a dendrite shape and sizes ranging from 5 to over $100 \mu \mathrm{m}$, Figure 1b. Their aspect is black, related to a very low crystallinity due to the nano structural organization within the graphene grains. Silver particles appeared as bright yellow dots with diameters predominantly between 1 to $2.5 \mu \mathrm{m}$, but significant submicron dots were observed, Figure $1 \mathrm{~b}$. The bright yellow aspect of silver micro and nano particles observed by CPOM was caused by the high crystallinity within them, a fact also reported in the literature [32,33].

Mixing the polymer with graphene-silver powder facilitates the smallest-particles adsorption on the sphere's surface. Figure 1c shows many spheres with a bright and compact black aspect due to the strong and uniform adhesion of the grapheme on the polymer surface. Silver particles having smaller diameters compared with the spheres is also attached to their surface being observed as bright spots. Some of the polymer spheres appear to remain uncoated, having the same halo aspect as observed in Figure 1a. 


\subsubsection{FTIR Spectroscopy}

The FTIR spectrum of PMMA had a peak at $1732 \mathrm{~cm}^{-1}$ that was due to acrylate carboxyl groups; at $1388 \mathrm{~cm}^{-1}$, this was due to $\mathrm{O}-\mathrm{CH}_{3}$ bending vibrations, and the peak at $1242 \mathrm{~cm}^{-1}$ was assigned to the twisting mode of the $-\mathrm{CH}_{2}$ group in PMMA. The FTIR peak of PMMA at $1439 \mathrm{~cm}^{-1}$ was assigned to the bending of $\mathrm{C}-\mathrm{H}$ bonds in the $-\mathrm{CH}_{3}$ group [34].

The infrared absorption spectrum of G-Ag was characterized by the existence of stripes with different peaks. The highest peak was at $3430 \mathrm{~cm}^{-1}$ (stretching and bending vibrations of $-\mathrm{OH}$ group), and $1275 \mathrm{~cm}^{-1}$ was assigned to $\mathrm{C}-\mathrm{OH}$, while the peak centered at $1600 \mathrm{~cm}^{-1}$ was assigned to $C=C$ bonds associated to the skeletal vibrations of unoxidized graphitic domains. The peak at $1720 \mathrm{~cm}^{-1}$ was assigned to $\mathrm{C}=\mathrm{O}$ bonds in the fragments of carboxylic acid and carbonyl. The G-Ag nanoparticles exhibited a new stripe at $1420 \mathrm{~cm}^{-1}$, resulting from the reduced $\mathrm{C}-\mathrm{N}$ stretching vibration of $\mathrm{G}-\mathrm{Ag}$. The peak at $1.320 \mathrm{~cm}^{-1}$ was assigned to $\mathrm{C}-\mathrm{O}-\mathrm{C}$. Further, the peak of absorbance at about $1.270 \mathrm{~cm}^{-1}$ was assigned to the $\mathrm{C}-\mathrm{OH}$ bond, and the new absorbance stripe at $1570 \mathrm{~cm}^{-1}$ was assigned to the skeletal vibration of the graphene sheets. The spectra of $\mathrm{P} 1$ and $\mathrm{P} 2$ samples showed the presence of the stripes specific to both PMMA and G-Ag (Figure 2).

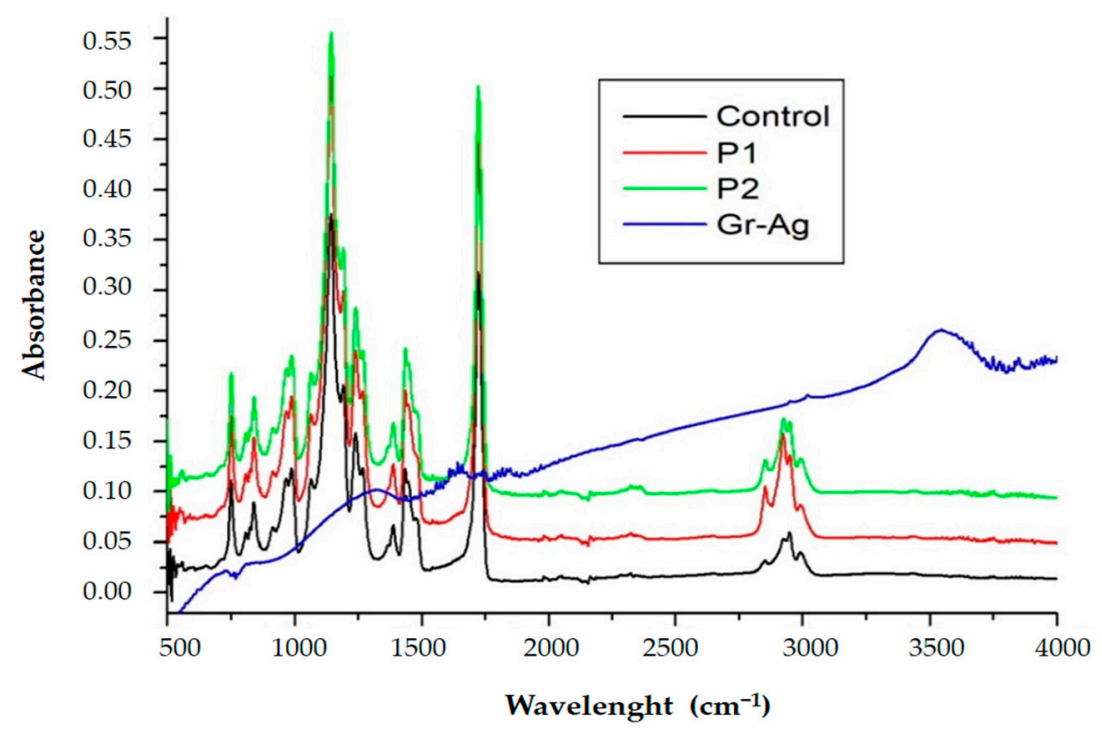

Figure 2. FTIR spectra of the PMMA polymer (enhanced with G-Ag and control).

\subsubsection{Scanning Electron Microscopy Investigations of the Acrylic Samples}

The dispersion and alignment of graphene nanoparticles into a polymer matrix play a key role in the properties of materials. In this regard, we characterized the PMMAGraphene by using scanning electron microscopy (SEM). The SEM images of the nanocomposite are shown in Figure $3 \mathrm{a}-\mathrm{c}$ to certify the even dispersion of the graphene within the PMMA matrix. According to these images, nanoparticles were well dispersed in the polymer phase as a function of the added percent (Figure $3 \mathrm{~b} .1 \%$ and Figure $3 \mathrm{c} 2 \%$ ). SEM images showed that PMMA-graphene composites had surface morphology similar to PMMA (Figure 3a) composites, as shown in Figure 3b,c. 


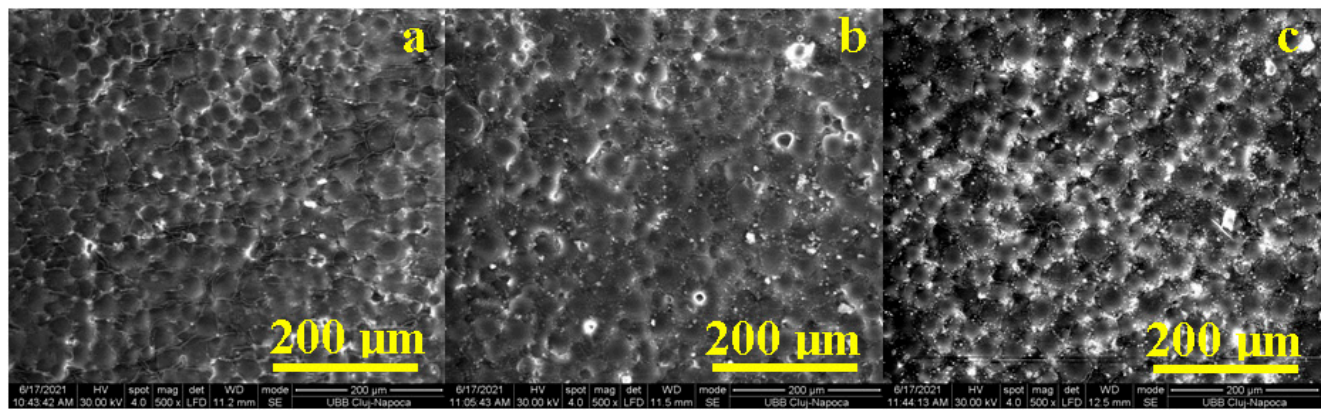

Figure 3. SEM images of the acrylic samples: (a)—PMMA, (b)—PMMA + 1\%GO and (c)—PMMA + $2 \%$ GO.

\subsection{Cell Viability}

As seen in Figure 4, the cells' viability was slightly decreased when exposed to the undiluted sample extract, though the decrease was not significant. Additionally, there were no significant viability differences between the experimental groups, as shown by one-way ANOVA $(p=0.98)$ and the Bonferroni posttest $(p=0.191, \mathrm{C}$ vs. P1, $p=0.137, \mathrm{C}$ vs. P2 and $p=0.054$, P1 vs. P2). The decrease was above $80 \%$ of the control values for samples $C$ and P1 and above $90 \%$ for sample P2. These results showed that the materials were rather well tolerated by the cells with no toxicity (viability below $70 \%$ of untreated control was considered toxic level).

C

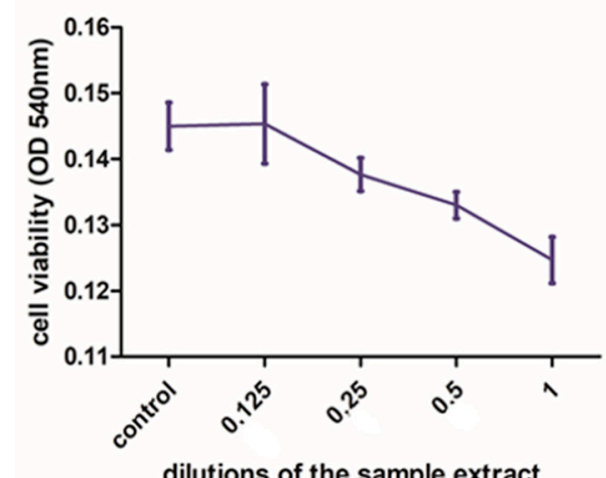

P2

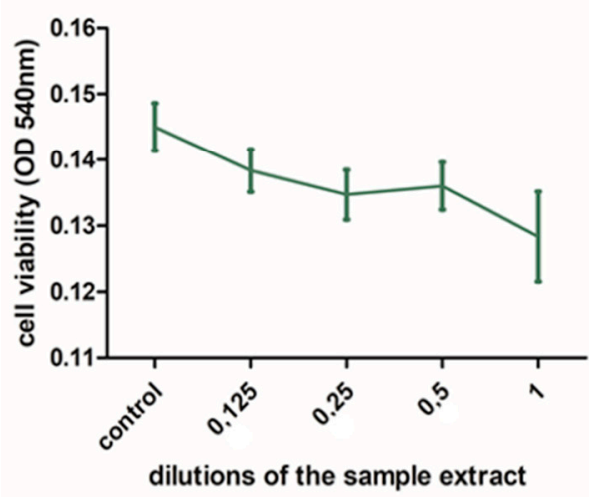

P1

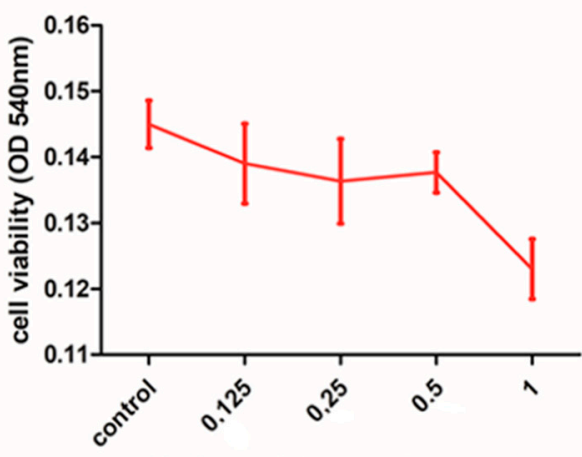

dilutions of the sample extract

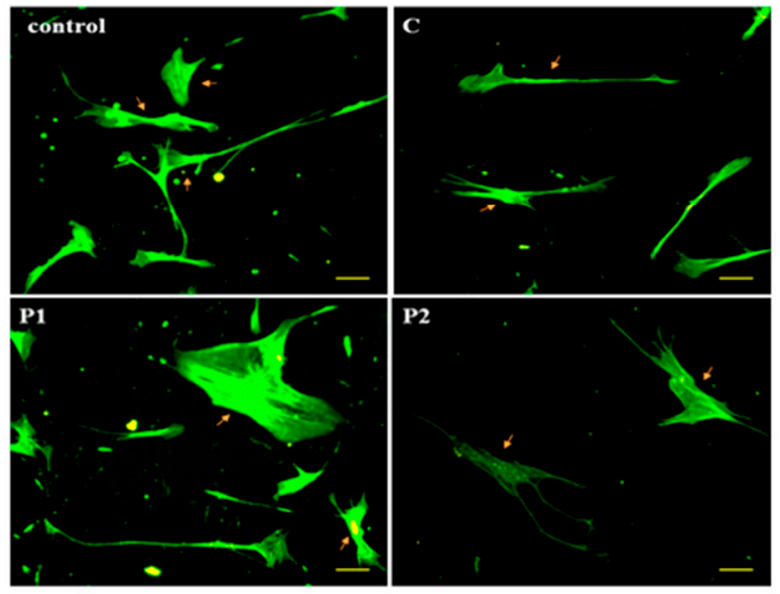

Figure 4. Cell-viability testing in the study groups based on dilutions of the sample extract. Cells were exposed to binary dilutions of the sample extract $\left(1 / 8,1 / 4, \frac{1}{2}\right.$ and undiluted) for $24 \mathrm{~h}$ and viability was evaluated by colorimetrical measurement of formazan production. Results are presented as OD. C = control sample, P1 = resin with $1 \mathrm{wt} \%$ graphene silver nanoparticles, P2 = resin with $2 \mathrm{wt} \%$ graphene silver nanoparticles. Comparative images of HGF cells treated with undiluted extract of each sample and then stained with Phaloidin-FITC are presented, bar $=20 \mu \mathrm{m}$. Yellow arrows show the normal morphological aspect of the HGF cells in all the groups. 
Phaloidin staining showed no alteration of the cytoskeleton as compared to the untreated control in all the treated groups. In all groups, the cells had a normal morphological aspect, they were adherent to the substrate, and they had multiple cytoplasmatic elongations, without signs of cellular distress.

\subsection{Antimicrobial Effect of the Acrylic Samples}

Antimicrobial activity was tested on three experimental groups: simple variant without light treatment, LED-treated variant, and Laser-treated variant. After incubation, for both bacterial strains, Porphyromonas gingivalis (Figure 5) and Enterococcus faecalis (Figure 6) large-inhibition zones were obtained. Significant differences were observed between the light-treated resins and the other specimens.

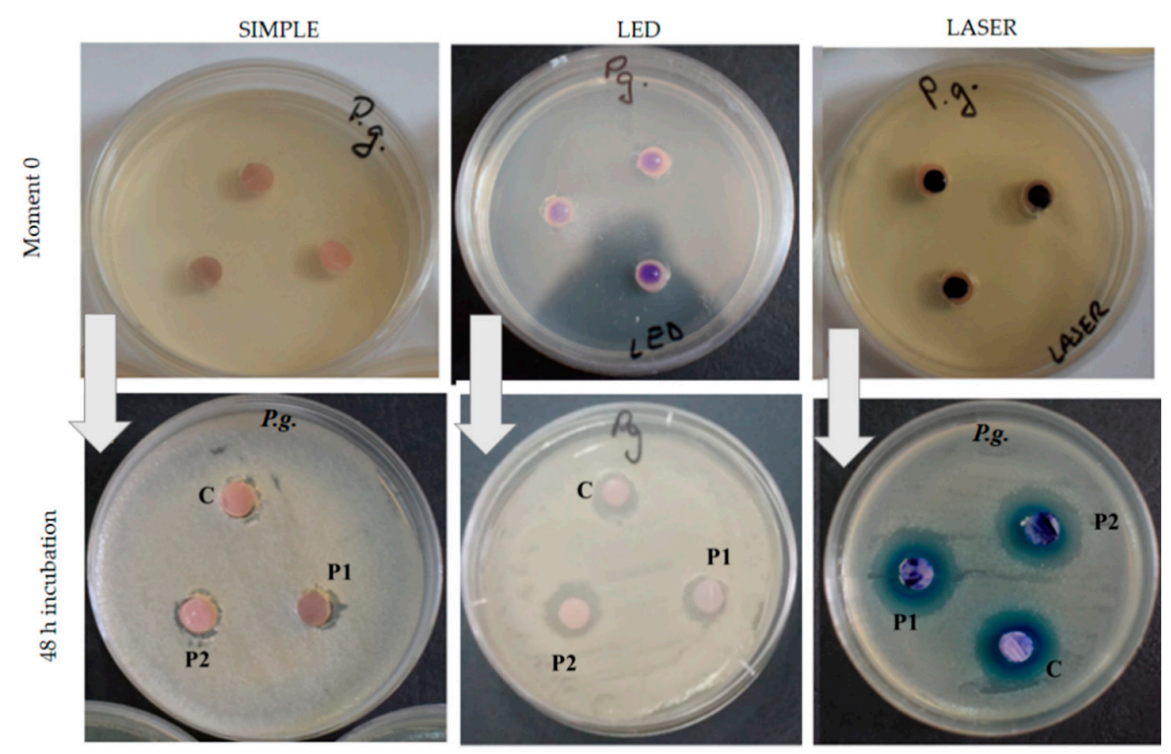

Figure 5. Antimicrobial activity of the samples (placed on the culture medium) against Porphyromonas gingivalis (Pg) in 48 incubation hours. (Three experimental variants: simple variant = without light treatment; LED-treated variant; Laser-treated variant).
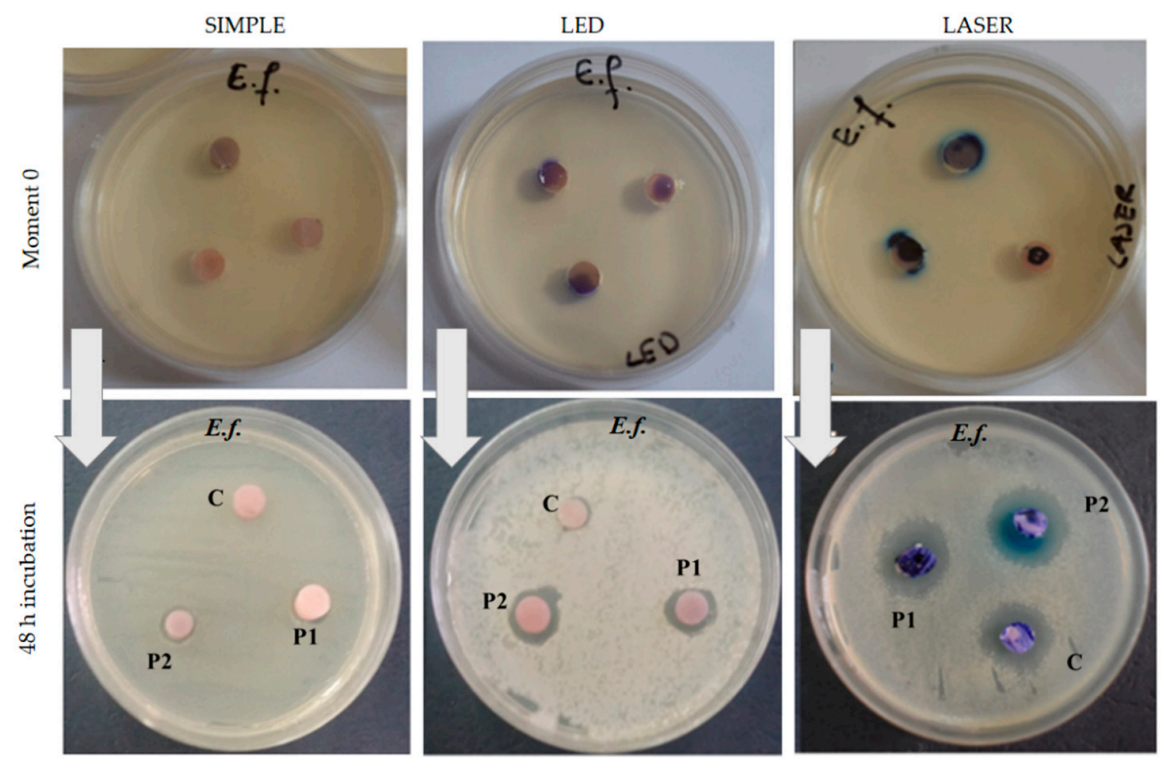

Figure 6. Antimicrobial activity of the samples (placed on the culture medium) against Enterococcus faecalis (Ef) in 48 incubation hours. (Three experimental variants: simple variant $=$ without light treatment; LED-treated variant; Laser-treated variant). 
The larger inhibition zones were found in P1 and P2 samples (PMMA enhanced with 1 or $2 \%$ nanoparticles) when the photosensitizer was placed on their surfaces and the resins were exposed to laser light (for both bacteria). Higher inhibitory effect was obtained for Porphyromonas gingivalis than for the Enterococcus faecalis (Figure 6) strain in all the study groups.

It was noticed that the diameter of the inhibition zone was larger for the P2 sample compared with the other ones. Additionally, the inhibition zone was much larger for Porphyromonas gingivalis than for Enterococcus faecalis. The laser-light treatment showed the largest inhibition effect in all experimental groups, for both bacterial cultures (Figure 7).

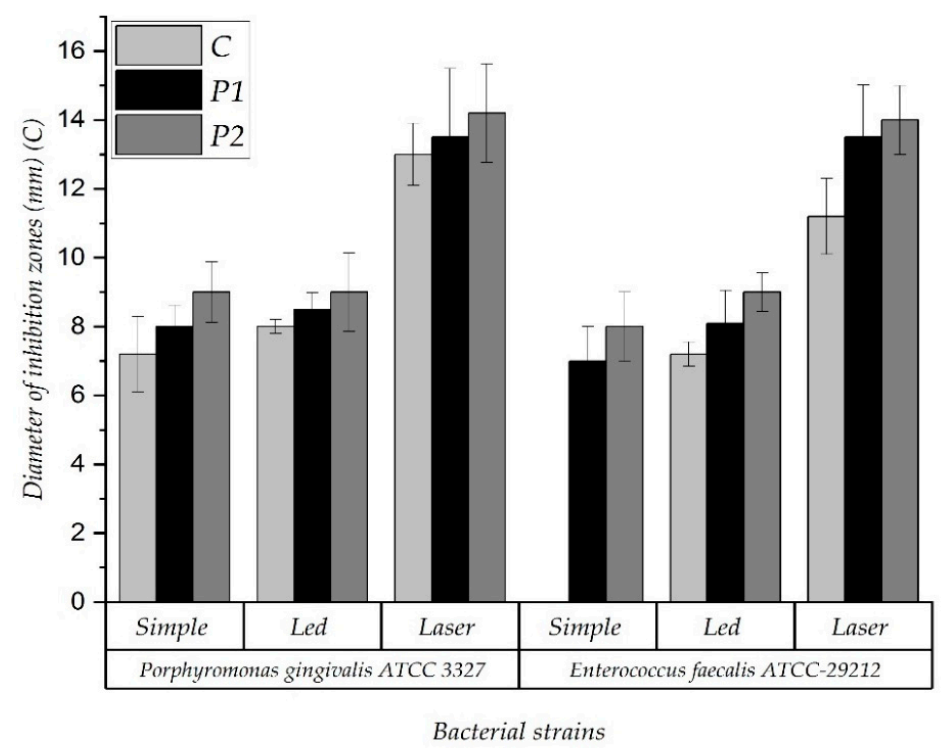

Figure 7. The antimicrobial activity of the samples in different experimental variants (simple, LED, and Laser) for Porphyromonas gingivalis ATCC 33277 and Enterococcus faecalis ATCC 29212 P1 and P2 samples compared to control (C).

The antimicrobial activity of the P1 samples, in different experimental variants (simple, LED, and Laser) for Porphyromonas gingivalis ATCC 33277 and Enterococcus faecalis ATCC 29212 , compared to control (simple variant), were not significantly different $(p=0.38156)$. The same results were observed from P2 and C comparison, with $p=0.22785$, without statistical differences.

\subsection{Scanning Electron Microscopy Investigations of the Bacterial Cells}

The aspect of the bacterial cells was analyzed on SEM images: rod shaped cells for P. gingivalis and ovoid cells for E. faecalis (Figure 8). 

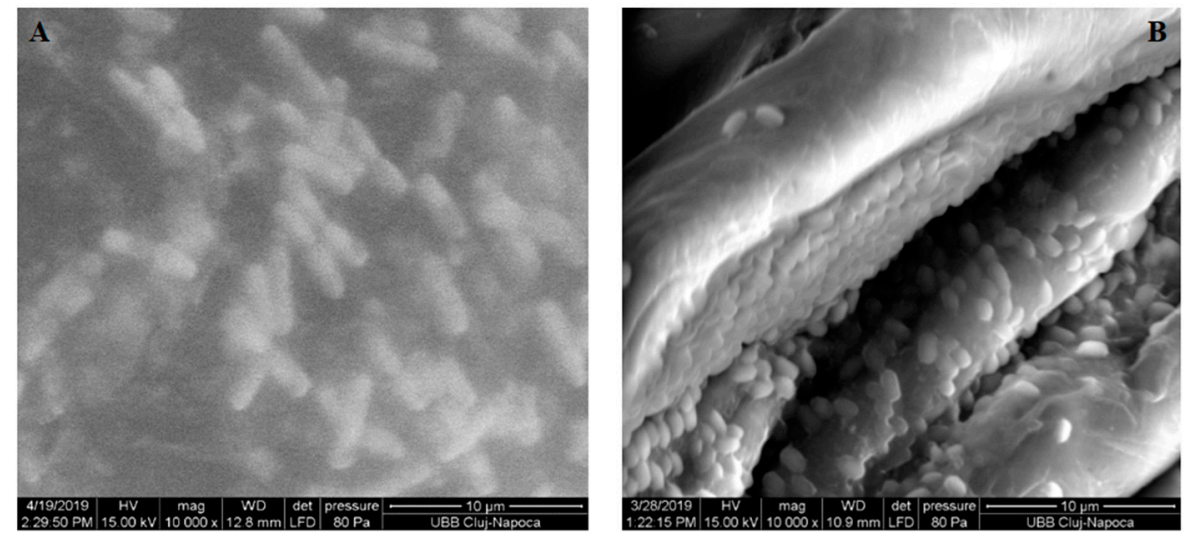

Figure 8. SEM investigation at 10,000 $\times$ magnitude for (A) Porphyromonas gingivalis ATCC 33277 and for (B) Enterococcus faecalis ATCC 29212.

\section{Discussion}

Like other bacteria that cause oral infections, halitosis-responsible bacteria have evident associations with denture wearers' discomfort. Still, there are no established protocols for the diagnosis and treatment of bad breath [35]. Halitosis in denture wearers is favored on one hand by poor oral hygiene and on the other hand by the presence of the denture (denture base-material characteristics, and of the saliva and tongue-reduced cleaning action). Systemic diseases together with impaired motility and memory loss can also influence the oral hygiene status in the elderly population [36].

In this study, possibilities to inactivate halitosis responsible bacteria using enhanced materials with and without association with photodynamic therapy were evaluated. PMMA acrylic resin enhanced with graphene silver nanoparticles showed antimicrobial effects on the studied bacterial strains, especially when using higher concentrations of nanoparticles ( $2 \%)$. Higher efficiency was found for the association of the studied resins with PDT and in particular the laser light. The studied resins were well tolerated by gingival fibroblasts, and cell viability remained above the toxic level after exposure to the samples.

Several bacterial species, mainly Gram-negative bacteria that colonize denture or dental plaque, are responsible for bad breath and periodontal disease: Porphyromonas gingivalis, Fusobacterium nucleatum, Prevotella intermedia, Solobacterium moorei, Prevotella (Bacteroides) melaninogenica, Treponema denticola, Porphyromonas endodontalis, Bacteroides loescheii, Enterobacteriaceae, Tannerella forsythensis (Bacteroides forsythus), Centipeda periodontii, Eikenella corrodens, Fusobacterium nucleatum vincentii, Fusobacterium nucleatum, Fusobacterium nucleatum polymorphum, and Fusobacterium periodonticum [37]. All these bacterial species can decompose proteins to aminoacids as methionine and cysteine in the oral cavity. These aminoacids are further metabolized, resulting in volatile sulphur compounds [38].

The bacterial strains used in the study were Porphyromonas gingivalis and Enterococcus faecalis. Porphyromonas gingivalis is a black-pigmented, Gram-negative, anaerobic, nonmotile, and pathogenic bacteria which belongs to the phylum Bacteroidetes [39]. At SEM investigation, P. gingivalis appeared as rod-shaped (Figure 7). Enterococcus faecalis is a Grampositive, catalase-negative, fermentative, non-spore-forming, facultative, anaerobic bacteria. At SEM, their cells were ovoid and about $0.5-1 \mu \mathrm{m}$ in diameter (Figure 7). They appear alone, in pairs, or in short chains and most strains are nonhemolytic and nonmotile [40]. Denture resins' surface chemistry and topography can favor bacterial adhesion [41]. Many authors aimed to improve the characteristics of denture resins by adding different materials to obtain antibacterial properties. The addition of graphene and silver nanoparticles to denture-base resins showed favorable effects against different bacterial strains [16], and materials with higher concentrations of additives exhibited better antimicrobial activity against the studied bacteria [23,42]. As both silver and graphene nanoparticles were shown to exhibit antibacterial effects, their association in this study was used in order to obtain an 
enhanced antimicrobial activity [11,43-45]. Graphene was also used for its anchoring and stabilizing effect for the silver nanoparticles. The percentage of graphene silver additives was selected to be 1 and $2 \%$, as the best results for resins reinforcement were reported for low nanofiller contents [46] and because of the color changes in the resins caused by their black color. For $1 \%$ addition of fillers, the color changes were discreet, while for the $2 \%$ loading the color changes were more evident. Higher concentrations could significantly affect the esthetics in visible areas. For these concentrations of additives, significant improvements of mechanical properties of the acrylic resin were obtained [18,23].

Photodynamic therapy (PDT), or light-activated therapy, is a treatment that uses a powerful light with a specific wavelength in association with a photosensitizer. PDT is a minimal and noninvasive treatment that was shown to significantly restrict the growth of or even to kill the microbes by photochemical reaction [47]. The photosensitive agent absorbs energy from the light and transfers it to oxygen, resulting in highly reactive oxygen species (ROS) that are effective against bacteria, fungi, and viruses [48,49]. Although PDT efficiency was mostly studied in tumor (malign cells) treatment, it has significant potential to be used in many preclinical and clinical fields [50]. PDT showed good results in the treatment of denture stomatitis [51], being more efficient on denture bases than on palatal mucosa [52].

Several studies were directed towards the efficiency of PDT against oral bacteria [53]. Other studies assessed the effect of the visible light irradiation without photosensitizers on bacteria, finding that light irradiation had a phototoxic effect on Gram-negative species, such as Porphyromonas gingivalis [54,55]. Chan demonstrated that a $60 \mathrm{~s}$ exposure to a $100 \mathrm{~mW}$ laser light at $665 \mathrm{~nm}$ in the presence of methylene blue eliminated up to 99$100 \%$ of Porphyromonas gingivalis cultures [56]. It has also been proved that PDT helps healing and the cleaning of oral tissues, including the root canals, by eliminating highly resistant species such as Enterococcus faecalis. A study that assessed the effect of PDT, using toluidine blue and a $635 \mathrm{~nm}$ light source on Enterococcus faecalis, showed a significant reduction in bacterial growth, although it was less effective than the combination of sodium hypochlorite $(\mathrm{NaOCl})$ irrigation and PDT in endodontic infections [57]. Lopez-Jimenez et al. demonstrated a reduction in Enterococcus faecalis biofilms, with severe damage and cell lysis on AFM images, when using methylene blue and a $670 \mathrm{~nm}$ diode laser or toluidine blue with a $628 \mathrm{~nm}$ LED light for $30 \mathrm{~s}$ [58]. Additionally, laser irradiation was effective in sealing dentinal tubules and eliminating bacteria that had penetrated to the depths of dentin [59].

Although PDT is generally considered a safe antibacterial approach without side reactions on oral tissues according to Komerick et al. [60], many studies reported pain and other side effects caused by the procedure [61]. In the present study, we aimed at assessing the effect of the photosensitive agent placed on PMMA (control and enhanced samples) and activated it outside the mouth before the contact with the studied bacterial strains in order to prevent pain and other side effects that can appear during direct-tissue exposure to red light.

The results obtained in the study showed that PMMA enhanced with graphene silver nanoparticles exhibited a higher inhibitory effect on halitosis responsible bacteria compared with control, with increased antimicrobial activity on the Porphyromonas gingivalis strain and when using higher concentrations of additives $(2 \mathrm{wt} \%)$. In the absence of the light treatment, the control had no effect on the Enterococcus faecalis strain, but exhibited a low antimicrobial activity on the Porphyromonas gingivalis strain. This could be caused by the polymer degree of conversion, the residual monomer, or the resin cytotoxicity [62]. Out of the two light sources used in this study, the use of the laser light had a higher influence on the growth inhibition of the two bacterial strains involved in halitosis. The materials tested in this study were well tolerated by the human normal gingival fibroblasts, and for P2 samples the cell viability was higher than for C and P1. CPOM investigation showed that the polymer spheres functionalization with silver-graphene powder was effective. The 
high degree of sphere coating assures an optimal behavior of the material regarding the biological effect evidenced in the research.

The practical aspect of the study could be that PDT using photosensitizer applied on dentures outside the oral cavity followed by their immediate placement into the mouth may be a safer, easier, and more efficient procedure for growth inhibition of different oral bacteria in denture wearers with no risks of pain, mucosal lesions, or other side effects. The results could be helpful especially for very old, disabled, or institutionalized patients. Patients that use orthodontic devices may also benefit from this treatment.

Oral health-promoting programs addressed to denture wearers could improve their oral health. An adequate oral and denture-hygiene routine together with denture overnight removal can reduce bad breath in denture wearers. Association of denture materials with other materials and procedures could be beneficial for obtaining a highly effective antibacterial activity, and for improving oral hygiene. Further studies regarding the exact mechanism of interaction between the light, photosensitizer, PMMA, and oral bacteria and also the influence of the material composition and surface characteristics, exposure time, and light wavelength are necessary. Future research should also explore the in vivo settings.

\title{
5. Conclusions
}

Bacterial-intensive growth and halitosis in denture wearers could be more easily and effectively counteracted by using new denture materials in association with non-invasive and clinically safer therapies. The addition of graphene silver nanoparticles to PMMA acrylic resins showed antimicrobial effects on halitosis-responsible bacteria. Extra-oral activation of a photosensitizing agent placed on denture base materials enhanced with graphene silver nanoparticles ( $1 \mathrm{wt} \%$ and $2 \mathrm{wt} \%)$ proved to increase the inhibition of bacteria associated with halitosis in acrylic denture wearers, especially when using laser light and higher nanoparticle concentrations ( $2 \mathrm{wt} \%)$. A higher inhibitory effect was found on the Porphyromonas gingivalis strain. According to these findings, PDT could be used, in association with materials with antibacterial properties, as a safer and more efficient alternative technique against bad breath and oral infections of denture wearers and of orthodontic device users. It may also be an easier way to control oral and denture hygiene especially for very old, disabled, or institutionalized patients and a possibility to improve their well-being and quality of life.

Author Contributions: Conceptualization, C.B., R.C., M.M.; investigation, C.B., R.C., S.B., D.P., L.M.D., M.L.M., A.C., O.L., F.C.; methodology, C.B., R.C., D.P.; supervision, M.B., M.M.; writing original draft, C.B., R.C., I.B., S.B., M.C., M.M., M.B. All authors have read and agreed to the published version of the manuscript.

Funding: This research received no external funding.

Data Availability Statement: Not applicable.

Conflicts of Interest: The authors declare no conflict of interest.

\begin{abstract}
Abbreviations
PDT—photodynamic therapy; PET—polyethylene teraphtalate; PMMA—polymethyl methacrylate; $\mathrm{H}_{2} \mathrm{~S}$ - hydrogen sulfide; $\left(\mathrm{CH}_{3}\right)_{2} \mathrm{~S}$ - dimethyl sulfide; $\mathrm{CH}_{3} \mathrm{SH}$ - methyl mercaptan; $\mathrm{NaOCl}$-natrium hypochlorite, LED—light emitting diode; LAD—light activated therapy; SEM—scanning electron microscopy; HGF-human gingival fibroblasts, G-Ag graphene silver.
\end{abstract}

\section{References}

1. Coulthwaite, L.; Verrain, J. Potential pathogenic aspects of denture plaque. Br. J. Biom. Sci. 2007, 64, 180-189. [CrossRef]

2. Sumi, Y.; Kagami, H.; Ohtsuka, Y.; Kakinoki, Y.; Haruguchi, Y.; Miyamoto, H. High correlation between the bacterial species in denture and pharyngeal microflora. Gerodontology 2003, 20, 84-87. [CrossRef] [PubMed]

3. Samnieng, P.; Palasuk, J.; Zaitsu, T.; Ueno, M.; Yoko, K. Oral malodor and its related factors in edentate elderly with and without dentures. Int. J. Clin. Prev. Dent. 2015, 11, 217-224. [CrossRef] 
4. Koshimune, S.; Awano, S.; Gohara, K.; Kurihara, E.; Ansai, T.; Takehara, T. Low salivary flow and volatile sulfur compounds in mouth air. Oral surgery, oral medicine, oral pathology. Oral Radiol. Endod. 2003, 96, 38-41. [CrossRef]

5. Kleinberg, I.; Wolff, M.; Codipilly, D. Role of saliva in oral dryness, oral feel and oral malodour. Int. Dent. J. 2002, 52, 236-240. [CrossRef]

6. Krespi, Y.; Shrime, M.; Kacker, A. The relationship between oral malodor and volatile sulfur compound-producing bacteria Otolaryngol. Head Neck Surg. Off. J. Am. Acad. Otolaryngol. Head Neck Surg. 2006, 135, 671-676. [CrossRef] [PubMed]

7. Devji, T. Professional tooth cleaning and scaling and root planing with oral hygiene instructions may reduce volatile sulfur compounds in patients with periodontal disease. J. Am. Dent. Assoc. 2018, 149, e26. [CrossRef]

8. Shagana, J.A. Evaluation of bacterial loads in removable dentures: A review. J. Pharm. Sci. Res. 2016, 8, 1117-1118.

9. Rostoka, D.; Kroiča, J.; Iriste, V.; Reinis, A.; Kuznetsova, V.; Teibe, U. Treatment of halitosis with mouth rinsing agents containing essential oils. Stomatologia 2012, 91, 27-34.

10. Köroğlu, A.; Şahin, O.; Kürkçüoğlu, I.; Dede, D.Ö.; Özdemir, T.; Hazer, B. Silver nanoparticle incorporation effect on mechanical and thermal properties of denture base acrylic resins. J. Appl. Oral Sci. 2016, 24, 590-596. [CrossRef]

11. Gad, M.M.; Fouda, S.M.; Al-Harbi, F.A.; Raustia, A. PMMA denture base material enhancement: A review of fiber, filler and nanofiller addition. Int. J. Nanomed. 2017, 12, 3801-3812. [CrossRef]

12. Fang, J.; Wang, C.; Li, Y.; Zhao, Z.; Mei, L. Comparison of bacterial adhesion to dental materials of polyethyleneterephthalate (PET) and polymethyl methacrylate (PMMA) using atomic force microscopy and scanning electron microscopy. Scanning 2016, 38, 665-670. [CrossRef] [PubMed]

13. Lessa, F.C.; Enoki, C.; Ito, I.Y.; Faria, G.; Matsumoto, M.A.; Nelson-Filho, P. In-vivo evaluation of the bacterial contamination and disinfection of acrylic baseplates of removable orthodontic appliances. Am. J. Orthod. Dentofacial. Orthop. 2007, 131, 705.e11-705.e17. [CrossRef]

14. Paolone, G.; Moratti, E.; Goracci, C.; Gherlone, E.; Vichi, A. Effect of finishing systems on surface roughness and gloss of full-body bulk resin -fill composites. Materials 2020, 13, 5657. [CrossRef] [PubMed]

15. Ionescu, A.C.; Cazzaniga, G.; Ottobelli, M.; Ferracane, J.L.; Paolone, G.; Brambilla, E. In vitro biofilm formation on resin-based composites under different surface conditions. J. Dent. 2018, 77, 78-86. [CrossRef] [PubMed]

16. Juan Carlos, F.A.; Rene, G.C.; Germán, V.S.; Laura Susana, A.T. Antimicrobial Poly (methyl methacrylate) with Silver Nanoparticles for Dentistry: A Systematic Review. Appl. Sci. 2020, 10, 4007. [CrossRef]

17. Lee, J.H.; Jo, J.K.; Kim, D.A.; Patel, K.D.; Kim, H.W.; Lee, H.H. Nano-graphene oxide incorporated into PMMA resin to prevent microbial adhesion. Dent. Mater. 2018, 34, e63-e72. [CrossRef]

18. Bacali, C.; Badea, M.; Moldovan, M.; Sarosi, C.; Nastase, V.; Baldea, I.; Chiorean, R.S.; Constantiniuc, M. The Influence of Graphene in Improvement of Physico-Mechanical Properties in PMMA Denture Base Resins. Materials 2019, 12, 2335. [CrossRef] [PubMed]

19. Chen, C.K.; Lee, M.C.; Lin, Z.I.; Lee, C.A.; Tung, Y.C.; Lou, C.W.; Law, W.C.; Chen, N.T.; Lin, K.A.; Lin, J.H. Intensifying the Antimicrobial Activity of Poly[2-(tert-butylamino)ethyl Methacrylate]/Polylactide Composites by Tailoring Their Chemical and Physical Structures. Mol. Pharm. 2019, 16, 709-723. [CrossRef]

20. Hoque, J.; Adhikary, U.; Yadav, V.; Samaddar, S.; Konai, M.M.; Prakas RGParamanandham, K.; Shome, B.R.; Sanyal, K.; Haldar, J. Chitosan derivatives active against multidrug-resistant bacteria and pathogenic fungi. In vivo evaluation as topical antimicrobials. Mol. Pharm. 2016, 13, 3578-3589. [CrossRef]

21. Chieruzzi, M.; Pagano, S.; Lombardo, G.; Marinucci, L.; Kenny, J.M.; Torre, L.; Cianetti, S. Effect of nanohydroxyapatite, antibiotic, and mucosal defensive agent on the mechanical and thermal properties of glass ionomer cements for special needs patients. $J$. Mater. Res. 2018, 33, 638-649. [CrossRef]

22. Roe, D.; Karandikar, B.; Bonn-Savage, N.; Gibbins, B.; Roullet, J.B. Antimicrobial surface functionalization of plastic catheters by silver nanoparticles. J. Antimicrob. Chemother. 2008, 61, 869-876. [CrossRef]

23. Bacali, C.; Baldea, I.; Moldovan, M.; Carpa, R.; Olteanu, D.E.; Filip, G.A.; Nastase, V.; Lascu, L.; Badea, M.; Constantiniuc, M.; et al. Flexural strength, biocompatibility and antimicrobial activity of a polymethyl methacrylate denture resin enhanced with graphene and silver nanoparticles. Clin. Oral Investig. 2020, 24, 2713-2725. [CrossRef] [PubMed]

24. Massey, V. The chemical and biological versatility of riboflavin. Biochem. Soc. Trans. 2000, 28, 283-296. [CrossRef]

25. Borgia, F.; Giuffrida, R.; Caradonna, E.; Vaccaro, M.; Guarneri, F.; Cannavò, S.P. Early and late onset side effects of photodynamic therapy. Biomedicines 2018, 6, 12. [CrossRef]

26. Sterer, N.; Feuerstein, O. Effect of visible light on malodour production by mixed oral microflora. J. Med. Microbiol. 2005, 54 Pt 12, 1225-1229. [CrossRef]

27. Soukos, N.S.; Som, S.; Abernethy, A.D.; Ruggiero, K.; Dunham, J.; Lee, C.; Doukas, A.; Goodson, J.M. Phototargeting Oral Black-Pigmented Bacteria. Antimicrob. Agents Chemother. 2005, 49, 1391-1396. [CrossRef]

28. Josefsen, L.B.; Boyle, R.W. Photodynamic therapy and the development of metal-based photosensitisers. Met. Based Drugs 2008, 2008, 276109. [CrossRef] [PubMed]

29. Biris, A.R.; Dervishi, E.; Ardelean, S.; Lazar, M.D.; Watanabe, F.; Biris, G.L.; Misan, I.; Biris, A.S. Synthesis of Ag-decorated, few-layer graphene structures over a novel $\mathrm{Ag} / \mathrm{MgO}$ catalytic system by radio-frequency chemical vapor deposition. Mater. Chem. Phys. 2013, 138, 454-461. [CrossRef]

30. ISO 10993-12; 2012 Biological Evaluation of Medical Devices_Part 12: Sample Preparation and Reference Materials; ISO: Geneva, Switzerland, 2012. 
31. Carpa, R.; Dragan-Bularda, M.; Muntean, V. General Microbiology-Practical Guide; Presa Universitara Clujeana: Cluj-Napoca, Romania, 2014; pp. 58-61. (In Romanian)

32. Rodríguez-León, E.; Íñiguez-Palomares, R.; Urrutia-Bañuelos, E.; Herrera-Urbina, R.; Tánori JMaldonado, A. Self-alignment of silver nanoparticles in highly ordered 2D arrays. Nanoscale Res. Lett. 2015, 10, 1-7. [CrossRef]

33. Shen, Y.; Dierking, I. Perspectives in Liquid-Crystal-Aided Nanotechnology and Nanoscience. Appl. Sci. 2019, 9, 2512. [CrossRef]

34. Gyanaranjan, S.; Niladri, S.; Sahua, D.; Swain, S.K. Nano gold decorated reduced graphene oxide wrapped polymethylmethacrylate for supercapacitor applications. RSC Adv. 2017, 7, 2137-2150.

35. Richter, J.L. Diagnostic and treatment of halitosis. Compend. Contin. Educ. Dent. 1996, 17, 370-372, $374-376$.

36. Kossioni, A.E.; Hajto-Bryk, J.; Janssens, B.; Maggi, S.; Marchini, L.; MCkenna, G.; Müller, F.; Petrovic, M.; Roller-Wirnsberger, R.E.; Schimmel, M.; et al. Practical guidelines for physicians in promoting oral health in frail older adults. J. Am. Med. Dir. Assoc. 2018, 19, 1039-1046. [CrossRef]

37. Porter, S.R.; Scully, C. Oral malodour (halitosis). BMJ 2006, 333, 632-635. [CrossRef]

38. Liu, J.; Ling, J.Q.; Wu, C.D. Cetylpyridinium chloride suppresses gene expression associated with halitosis. Arch. Oral Biol. 2013, 58, 1686-1691. [CrossRef] [PubMed]

39. Lu, W.; Gu, J.-Y.; Zhang, Y.-Y.; Gong, D.-J.; Zhu, Y.-M.; Sun, Y. Tolerance induced by Porphyromonas gingivalis may occur independently of TLR2 and TLR4. PLoS ONE 2018, 13, e0200946. [CrossRef]

40. Colaco, A.S. Extreme resistance of Enterococcus faecalis and its role in endodontic treatment failure. Prog. Med. Sci. 2018, 2, 9-13. [CrossRef]

41. Kumari, S.V.; Taruna, M.; Chittaranjan, B.; Reddy, S.M.; Reddy, K.K.; Kulkarni, G. A qualitative analysis to compare the effects of surface machining of conventional denture base resin and two soft liners: A scanning electron microscopic study. J. Clin. Diagn. Res. 2015, 9, ZC30-ZC34. [CrossRef]

42. Şuhani, M.F.; Băciuţ, G.; Băciuţ, M.; Şuhani, R.; Bran, S. Current perspectives regarding the application and incorporation of silver nanoparticles into dental biomaterials. Clujul Med. 2018, 91, 274-279. [CrossRef]

43. Sun, L.; Yan, Z.; Duan, Y.; Zhang, J.; Liu, B. Improvement of the mechanical, tribological and antibacterial properties of glass ionomer cements by fluorinated graphene. Dent. Mater. 2018, 34, e115-e127. [CrossRef]

44. Li, J.; Wang, G.; Zhu, H.; Zhang, M.; Zheng, X.; Di, Z.; Liu, X.; Wang, X. Antibacterial activity of large-area monolayer graphene film manipulated by charge transfer. Sci. Rep. 2014, 4, 4359. [CrossRef]

45. Jaworski, S.; Wierzbicki, M.; Sawosz, E.; Jung, A.; Gielerak, G.; Biernat, J.; Jaremek, H.; Łojkowski, W.; Woźniak, B.; Wojnarowicz, J.; et al. Graphene Oxide-Based Nanocomposites Decorated with Silver Nanoparticles as an Antibacterial Agen. Nanoscale Res. Lett. 2018, 13, 116. [CrossRef]

46. Vallé, C.; Kinloch, I.A.; Young RJWilson, N.R.; Rourke, J.P. Graphene oxide and base-washed graphene oxide as reinforcements in PMMA nanocomposites. Compos. Sci. Technol. 2013, 88, 158-164. [CrossRef]

47. Jiang, X.; Fan, Z.; Yu, Y.; Shao, C.; Suo, Y.; Wei, X.; Zhou, Y. Toluidine blue O and porphyrin-mediated photodynamic therapy on three main pathogenic bacteria of periodontitis using portable LED phototherapy device. J. Innov. Opt. Health Sci. 2015, 8, 1550017. [CrossRef]

48. Hamblin, M.R.; Hassan, T. Photodynamic therapy: A new antimicrobial approach to infectious disease? Photochem. Photobiol. Sci. 2004, 3, 436-450. [CrossRef]

49. Gambarini, G.; Plotino, G.; Grande, N.; Nocca, G.; Lupi, A.; Giardina, B.; De Luca, M. TestarellI. In vitro evaluation of the cytotoxicity of FotoSan light-activated disinfection on human fibroblasts. Med. Sci. Monit. 2011, 17, MT21-MT25. [CrossRef]

50. Kato, H. History of photodynamic therapy past, present and future. Gan Kagaku Ryoho 1996, 23, 8-15.

51. Javed, F.; Samaranayake, L.P.; Romanos, G.E. Treatment of oral fungal infections using antimicrobial photodynamic therapy: A systematic review of currently available evidence. Photochem. Photobiol. Sci. 2014, 13, 726-734. [CrossRef]

52. Mima, E.G.; Vergani, C.E.; Machado, A.L.; Massucato, E.M.S.; Colombo, A.L.; Bagnato, V.S.; Pavarina, A.C. Comparison of photodynamic therapy versus conventional antifungal therapy for the treatment of denture stomatitis: A randomized clinical study. Clin. Microbiol. Infect. 2012, 18, E380-E388. [CrossRef]

53. Amoian, B.; Mirzaee, A.; Hosseini, S.M. Assessment of the effect of photodynamic therapy on treatment of moderate-to-severe periodontitis; a randomized clinical trial study. Glob. J. Health Sci. 2016, 9, 83. [CrossRef]

54. Feuerstein, O.; Persman, N.; Weiss, E.I. Phototoxic effect of visible light on Porphyromonas gingivalis and Fusobacterium nucleatum: An in vitro study. Photochem. Photobiol. 2004, 80, 412-415. [CrossRef]

55. Fukui, M.; Yoshioka, M.; Satomura, K.; Nakanishi, H.; Nagayama, M. Specific-wavelength visible light irradiation inhibits bacterial growth of Porphyromonas gingivalis. J. Periodontal. Res. 2008, 43, 174-178. [CrossRef]

56. Chan, Y.; Lai, C.H. Bactericidal effects of different laser wavelengths on periodontopathic germs in photodynamic therapy. Lasers Med. Sci. 2003, 18, 51-55. [CrossRef]

57. Tennert, C.; Feldmann, K.; Haamann, E.; AL-Ahmad, A.; Follo, M.; Wrbas, K.T.; Hellwig, E.; Altenburger, M.J. Effect of photodynamic therapy (PDT) on Enterococcus faecalis biofilm in experimental primary and secondary endodontic infections. BMC Oral Health 2014, 14, 132. [CrossRef] [PubMed]

58. Lopez-Jimenez, L.; Fuste, E.; Martinez-Garriga, B.; Arnabat-Dominguez, J.; Vinuesa, T.; Vinas, M. Effects of photodynamic therapy on Enterococcus faecalis biofilms. Lasers Med. Sci. 2015, 30, 1519-1526. [CrossRef] 
59. Jurič, I.B.; Anić, I. The use of lasers in disinfection and cleanliness of root canals: A review. Acta Stomatol. Croat. 2014, 48, 6-15. [CrossRef]

60. Komerick, N.; Curnow, A.; Macrobert, A.J.; Hopper, C.; Speight, P.M.; Wilson, M. Fluorescence biodistribution and photosensitizing activity of toluidine blue on rat buccal mucosa. Lasers Med. Sci. 2002, 17, 86-92. [CrossRef] [PubMed]

61. Ang, J.M.; Riaz, I.B.; Kamal, M.U.; Paragh, G.; Zeitouni, N.C. Photodynamic therapy and pain: A systematic review. Photodiagnosis Photodyn. Ther. 2017, 19, 308-344. [CrossRef]

62. Kraigsley, A.M.; Tang, K.; Lippa, K.A.; Howarter, J.; Gibson, S.L.; Lin, N.J. Effect of polymer degree of conversion on Streptococcus mutans biofilms. Macromol. Biosci 2012, 12, 1706-1713. [CrossRef] [PubMed] 